\title{
Review of: "Tutorial Review: Evidence for the Memory Color Effect, 1923-2016"
}

\author{
$\mathrm{el} \mathrm{el}^{1}$ \\ 1 Charité Universitätsmedizin Berlin
}

Potential competing interests: The author(s) declared that no potential competing interests exist.

Very interesting paper. 